Egyptian Journal of Aquatic Biology \& Fisheries

Zoology Department, Faculty of Science,

Ain Shams University, Cairo, Egypt.

ISSN $1110-6131$

Vol. 25(3): $77-83$ (2021)

www.ejabf.journals.ekb.eg

\title{
Effect of Mao (Antidesma sp.) juice on growth performance and resistance against Streptococcus spp. in the Nile tilapia (Oreochromis niloticus)
}

\author{
Narong Kamolrat ${ }^{1, *}$ Peechanika Chopjit ${ }^{2}$ and Wassana Prisingkorn ${ }^{3}$ \\ ${ }^{1}$ Faculty of Natural Resources and Argo-Industry, Kasetsart University Chalermphrakiat Sakon \\ nakhon Province Campus, Sakon Nakhon, Thailand \\ 2. Faculty of Public health, Kasetsart University Chalermphrakiat Sakon nakhon Province \\ Campus, Sakon Nakhon, Thailand. \\ 3. Faculty of Agriculture, Khon Kaen University, Khon Kaen, Thailand.
}

"Corresponding Author: narong.ka@ku.th

\section{ARTICLE INFO}

Article History:

Received: March 18, 2021

Accepted: May 2, 2021

Online: May 26, 2021

Keywords:

Mao;

Antidesma sp.;

Streptococcus spp.;

Oreochromis niloticus;

Resistance;

Growth performance

\section{ABSTRACT}

The present study investigated the effect of Mao (Antidesma sp.) juice concentration on the growth rate and infection resistance to Streptococcus spp. in the Nile tilapia fish with an initial weight of $12.65 \pm 0.14 \mathrm{~g}$. The experiment was divided into the control (0), 60, 40 and 20\% Mao juice mixed feed powder, respectively. At the end of the 60 day experimental period, the average daily growth values were $0.49 \pm 1.22,0.29 \pm 0.71,0.39 \pm$ 0.78 and $0.43 \pm 0.48 \mathrm{gD}^{-1}$, respectively, the specific growth rates were 5.62 $\pm 0.66,4.75 \pm 0.49,5.25 \pm 0.55$ and $5.41 \pm 0.39 \% \mathrm{D}^{-1}$, respectively, feed conversion ratios were $1.83 \pm 2.11,2.78 \pm 0.88,2.13 \pm 0.67$ and $1.68 \pm 0.53$, respectively, and the survival rates were $76.19 \pm 0.32,84.52 \pm 0.47,82.14 \pm$ 0.73 and $94.05 \pm 0.47 \%$, respectively. There were significant $(\mathrm{P}<0.05)$ differences. The results from injection of Streptococcus agalactiae and Streptococcus ineae in Nile tilapia fed at the $20 \%$ Mao juice level had the lowest cumulative mortality at $43.33 \pm 5.77 \%$ and $70.00 \pm 10.00 \%$, respectively. The results showed that the $20 \%$ Mao juice level had a positive effect on the growth rate and resistance to $S$. agalactiae

\section{INTRODUCTION}

Nile tilapia is one of the most economically important freshwater fish in the world. It is widely cultured because it can adapt to new environments, eats almost kinds of food, grows quickly and is easy to breed. In Thailand tilapia is a popular fish for household consumption and for trade, both domestically and abroad, with production increasing annually, making it possible to find tilapia fish in every region of the country and especially in the northeastern region, where tilapia aquaculture occurs in every province. However, periodic epidemics are a problem from bacterial infection by the group of 
Streptococcus spp. with Streptococcus agalactiae and Streptococcus ineae (Suanyuk $\boldsymbol{e t}$ al., 2008) causing substantial losses to tilapia farmers.

The Streptococcus spp. are a group of Gram-positive bacteria which cause chronic disease and inflammation and wounds in various organs of the body (Pungpang $\boldsymbol{e t}$ al, 2007), causing the death of many cultured tilapia (Al-Harbi, 1994; Perera et al., 1994; Shoemaker et al., 2000; Sirimanaponga et al., 2018). Normal treatment uses antibiotics, but there is increasing concern that these affect antimicrobial resistance in consumers of tilapia products. Therefore, the selection of local herbs and fruits is one option for the prevention and treatment of the fish diseases. The current study focused on a local plant called 'Mao', whose fruit grows in grouped berries and is popular in the northeast where it is processed into wine. The antioxidant properties of the anthocyanins, gallic acid, catechin, epicatechin and procyanidin in Mao have been reported (Puangpronpitag $\boldsymbol{e t}$ al., 2008; Sakhunkhu \& Sudham, 2014). Mao also contains antibacterial flavoniod compounds that help to reduce inflammation (Butkhup \& Samappito, 2008), as well as vitamins such as vitamin B1, B2, C and E. The study conducted by Kamolrat \& Chobjit (2018) tested Mao juice against $S$. agalactiae and S. ineae in vitro and found that Mao juice was resistant to $S$. agalactiae, at an equivalent level to oxytetracycline.

The current research involved feeding Mao juice to tilapia fish at different concentrations and studying the growth rate and any increased ability to resist infection against Streptococcus spp. with the aim of replacing traditional antibiotics with substances from local medicinal plants.

\section{MATERIALS AND METHODS}

1. The experimental group was divided into 4 experimental groups. Each group was fed different powdered food mixes containing different levels of Mao juice being the control group (0), 60, 40 and 20\%, respectively that were designated as C, T1, T2 and T3 respectively.

2. The experiment animals were 360 tilapias with initial weight of $12.65 \pm 0.14 \mathrm{~g}$, with 3 replicates of 30 fish each.

3. The rate of feeding was maintained at a constant rate of $3 \%$ body weight over the period of the experiment, feeding twice a day at 8:00 AM and 4:00 PM with water exchange (80\%) every 2 days in the raised tanks.

4. Growth data based on weight were recorded for a sample of 20 fish every 7 days up to 60 days. The parameters were determined using the following equations:

4.1 Feed conversion ratio $(\boldsymbol{F C R})=\frac{\boldsymbol{F}}{\left(B W_{t}-B W_{0}\right)}$

4.2 Average daily growth $(\boldsymbol{A D G})\left(\boldsymbol{g} \boldsymbol{D}^{-\mathbf{1}}\right)=\left[\frac{B W_{t}-\boldsymbol{B} \boldsymbol{W}_{o}}{\boldsymbol{t}}\right]$

4.3 Weight gain (WG) $(\boldsymbol{g})=\left[\boldsymbol{B} \boldsymbol{W}_{\boldsymbol{t}}-\boldsymbol{B} \boldsymbol{W}_{\boldsymbol{o}}\right]$ 
4.4 Specific growth rate $\left(\mathbf{S G R}_{\mathrm{BW}}\right)\left(\% D^{-\mathbf{1}}\right)=\left[\frac{\left(\operatorname{InB} \boldsymbol{W}_{\boldsymbol{t}}-\operatorname{In} B \boldsymbol{W}_{\boldsymbol{o}}\right)}{t}\right] \boldsymbol{x} \mathbf{1 0 0}$

4.5 Survival rate $(\mathrm{SR})(\%)=\left[\frac{N_{t}}{N_{0}}\right] \boldsymbol{x} \mathbf{1 0 0}$

5. After 60 days of cultivation, an antibacterial test was conducted on 10 fish randomly selected from each experimental unit by injecting each fish with $S$. agalactiae and $S$. ineae at a concentration of $10^{8} \mathrm{CFU}(0.1 \mathrm{ml}$ each $)$ and cumulative mortality was determined for 7 days.

6. The data obtained were analyzed for experimental group differences using analysis of variance (ANOVA) at the $95 \%$ confidence level $(\mathrm{P}<0.05)$ and mean differences between batches of experiments were compared using Scheffe's method in the SPSS software program (version 22).

\section{RESULTS}

\section{Growth rate}

For the tilapia fish in each experiment group $\left(\mathrm{C}, \mathrm{T}_{1}, \mathrm{~T}_{2}\right.$ and $\left.\mathrm{T}_{3}\right)$ at the end of the trial, the mean final weights were $41.83 \pm 0.52,29.96 \pm 0.71,35.95 \pm 0.56$ and $38.35 \pm$ $0.41 \mathrm{~g}$, respectively. The mean WG values were $29.18 \pm 0.73,17.31 \pm 0.97,23.30 \pm 0.68$ and $25.70 \pm 0.37 \mathrm{~g}$, respectively, with significant differences among the groups and the control group having the best growth rate (Table 1).

\section{Feed conversion ratio}

The FCR values were calculated at the end of all trial groups. The mean values for the $\mathrm{C}, \mathrm{T}_{1}, \mathrm{~T}_{2}$ and $\mathrm{T}_{3}$ groups were $1.83 \pm 2.11,2.78 \pm 0.88,2.13 \pm 0.67$ and $1.68 \pm 0.53$, respectively, and these were significantly different in each group and the best group was $\mathrm{T}_{3}$ (Table 1).

\section{Average daily growth}

The ADG values for the $C, T_{1}, T_{2}$ and $T_{3}$ groups were $0.49 \pm 1.22,0.29 \pm 0.71$, $0.39 \pm 0.78$ and $0.43 \pm 0.48 \mathrm{gD}^{-1}$, respectively. The control group was the highest and was significantly different from $\mathrm{T}_{1}$, but not from $\mathrm{T}_{2}$ and $\mathrm{T}_{3}$ (Table $\mathbf{1}$ ).

\section{Specific growth rate}

The SGR values for the $\mathrm{C}, \mathrm{T}_{1}, \mathrm{~T}_{2}$ and $\mathrm{T}_{3}$ groups were $5.62 \pm 0.66,4.75 \pm 0.49 \%$, $5.25 \pm 0.55$ and $5.41 \pm 0.39 \% \mathrm{D}^{-1}$, respectively. All groups were significantly different with the control group having the highest specific growth rate (Table 1).

\section{Survival rate}


The $S R$ values for the $C, T_{1}, T_{2}$ and $T_{3}$ groups were $76.19 \pm 0.32,84.52 \pm 0.47$, $82.14 \pm 0.73$ and $94.05 \pm 0.47 \%$, respectively. All groups were significantly different with the $\mathrm{T}_{3}$ group having the highest survival rate (Table 1).

Table 1. Growth performance of the Nile tilapia

\section{Treatment}

\begin{tabular}{lllll} 
& Control & T1 (60\%) & T2 (40\%) & T3 (20\%) \\
\hline Initial Weight (g) & $12.65 \pm 0.14$ & $12.65 \pm 0.14$ & $12.65 \pm 0.14$ & $12.65 \pm 0.14$ \\
Final Weight (g) & $41.83 \pm 0.52^{\mathrm{a}}$ & $29.96 \pm 0.71^{\mathrm{d}}$ & $35.95 \pm 0.56^{\mathrm{c}}$ & $38.35 \pm 0.41^{\mathrm{b}}$ \\
Weight gain (g) & $29.18 \pm 0.73^{\mathrm{a}}$ & $17.31 \pm 0.97^{\mathrm{d}}$ & $23.30 \pm 0.68^{\mathrm{c}}$ & $25.70 \pm 0.37^{\mathrm{b}}$ \\
ADG (g/day) & $0.49 \pm 1.22^{\mathrm{a}}$ & $0.29 \pm 0.71^{\mathrm{b}}$ & $0.39 \pm 0.78^{\mathrm{a}}$ & $0.43 \pm 0.48^{\mathrm{a}}$ \\
FCR & $1.83 \pm 2.11^{\mathrm{c}}$ & $2.78 \pm 0.88^{\mathrm{a}}$ & $2.13 \pm 0.67^{\mathrm{b}}$ & $1.68 \pm 0.53^{\mathrm{d}}$ \\
SGR (\%/day) & $5.62 \pm 0.66^{\mathrm{a}}$ & $4.75 \pm 0.49^{\mathrm{d}}$ & $5.25 \pm 0.55^{\mathrm{c}}$ & $5.41 \pm 0.39^{\mathrm{b}}$ \\
SR (\%) & $76.19 \pm 0.32^{\mathrm{d}}$ & $84.52 \pm 0.47^{\mathrm{b}}$ & $82.14 \pm 0.73^{\mathrm{c}}$ & $94.05 \pm 0.47^{\mathrm{a}}$
\end{tabular}

*Note: Mean \pm SE in rows with different lowercase superscripts are significantly $(\mathrm{P}<0.05)$ different compared using Scheffe' test.

\section{Cumulative mortality}

After the injection of both $S$. agalactiae and $S$. ineae for 7 days, tilapia infected with $S$. agalactiae in the experimental groups $\mathrm{C}, \mathrm{T}_{1}, \mathrm{~T}_{2}$ and $\mathrm{T}_{3}$ had cumulative mortality rates of $90.00 \pm 0.0,86.67 \pm 5.77,56.67 \pm 5.77$ and $43.33 \pm 5.77 \%$, respectively. For the same groups, tilapia infected with $S$. ineae had cumulative mortality rates of $93.33 \pm 5.77$, $100 \pm 0.0,93.33 \pm 5.77$ and $70.00 \pm 10.0 \%$, respectively (Fig. 1).
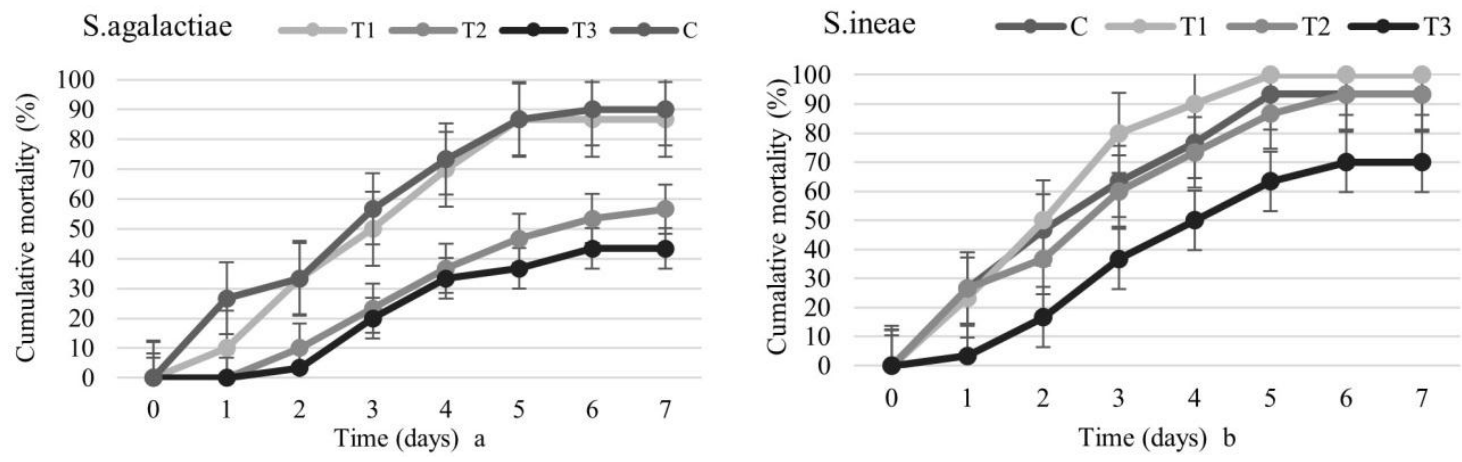

Fig.1 Cumulative mortality of tilapia after challenge testing with "S. agalactiae" (a) and "S. ineae" (b) for 7 days 


\section{DISCUSSION}

The control group had the highest growth rates but the survival rate from rearing was less and there was a significant difference for all groups. Group $\mathrm{T}_{3}$ had the highest survival rates and FCR during raising based 60 days of culture. The weather conditions during the trial period (as Thailand was entering the cooler winter season) affected the temperature of the water in the culture tank. There was fish mortality in the control group that was not exposed to feed containing Mao juice during the experiment. Normally, when the temperature drops, the fish's dietary intake and immune system response will decrease, resulting in the fish becoming infected and showing symptoms of illness. However, on the other hand, the groups receiving the feed mix with Mao juice had higher survival rates, especially the $\mathrm{T}_{3}$ group for which a good growth rate and high survival rate were recorded. The survival rate of tilapia in the group fed with the Mao mixed was better than for the control group because of several vitamins in the Mao juice, especially vitamin $\mathrm{C}$ (ascorbic acid), which has a sour taste. These may have enhanced the immune system as tannins that have antibacterial effects have also been found to give astringency and a bitter taste. However, the taste in the Mao juice affected the amount eaten by the fish perhaps due to the impact of the bitterness on their taste buds. Exposure to chemicals stimulates brain activity to order the control of food intake, with the taste buds of hard bony fish being found mostly on the lips, throat, gums and nose. Thus, the bitterness would have been especially strong with the $40 \%$ and $60 \%$ mixtures of Mao juice, resulting in the fish eating less food than usual. However, with the feed mix with $20 \%$ Mao juice, the fish were able to accept the feed, based on the results for GR, FCR and SR.

In the resistance test using $S$. agalactiae and $S$. ineae, the $\mathrm{T}_{3}$ group (20\% Mao juice) had the lowest cumulative mortality rate $(43.33 \pm 5.77 \%)$ when injected with $S$. agalactiae. S. ineae produced a high cumulative mortality rate of $70.00 \pm 10.0 \%$. These results showed that Mao juice could act as an immunosuppressive but could not reach the level of antibacterial protection. Because the Mao juice had been obtained from fresh fruit, the active ingredient was not high. Therefore, tilapia would need to be fed the Mao mix for an extended period to achieve an anti-bacterial effect. The tilapia appeared to have received an appropriate level of Mao because following infection with S. agalactiae and $S$. ineae, the fish were more resistant to the infection. The additional health supplements such as vitamin $\mathrm{C}$ in the Mao juice could help to reduce toxicity and build immunity in aquatic animals. Vitamin $\mathrm{C}$ is accumulated in white blood cells and can help promote the work of white blood cells via the neutrophils for better elimination of pathogens (Ai et al., 2006 ; Ibrahem et al., 2010). The Mao water contains phenolic compounds such as gallic acid, coumaric acid, catechin, caffeic acid, syringic acid and ferulic acid that promote antioxidant properties and can reduce inflammation by reducing the destruction of harmful free radicals and thus reducing the risk of disease (Peng $\boldsymbol{e t}$ al., 
2006; Puangpronpitag et al., 2008; Donthuan et al., 2018;). Tannins as a polyphenol compound can stop bleeding and suppress the blisters from burns, as the antioxidant has the ability to destroy bacteria and fungi (Bravo, 1998; Sakhunkhu \& Sudham, 2014; Omnes et al., 2017). Other minerals present include calcium, magnesium, phosphorus, potassium, iron, copper and zinc (Judprasong et al., 2013).

\section{CONCLUSION}

When $20 \%$ of Mao juice was added to the feed of tilapia fish, the growth and survival rates improved as their ability to resist $S$. agalactiae and $S$. ineae. Thus, supplementing the tilapia diet with Moa juice was suitable as an immune booster and but the juice as a natural substance, requires some time to accumulate to effective levels in the fish. This study provided preliminary testing to examine the positive effects of Mao juice. Follow up research should investigate the form of Mao juice extract and study the active ingredients as an alternative to local plants that can be used to increase the survival rate of tilapia and to reduce the use of antibiotics.

\section{ACKNOWLEDGMENT}

The Kasetsart University Research and Development Institute (KURDI), Bangkok, Thailand provided funding for this research

\section{REFERENCES}

Ai, Q.H.; Mai, K.S.; Tan, B.P. et al. (2006). Effects of dietary vitamin C on survival, growth, and immunity of large yellow croaker, Pseudosciaena crocea. Aquaculture, 261: 327-336. https://doi.org/10.1016/j.aquaculture.2006.07.027

Al-Harbi, A.H. (1994). First isolation of Streptococcus sp. from hybrid tilapia (Oreochromis niloticus x O. aureus) in Saudi Arabia. Aquacult., 128: 195- 201. https://doi.org/10.1016/0044-8486(94)90308-5

Bravo, L. (1998). Polyphenols: chemistry, dietary sources, metabolism, and nutritional significance. Nutr. Rev., 56(11): 317-33. DOI: 10.1111/j.1753-4887.1998.tb01670.x.

Butkhup, L. and Samappito, S. (2008). An analysis on flavonoids contents in Mao Luang fruits of fifteen cultivars (Antidesma bunius), grown in northeast Thailand. Pakistan Journal of Biology Science, 11(7): 996-1002. DOI: 10.3923/pjbs.2008. 996.1002

Donthuan, J.; Phusrithan, A. and Tebumrung, P. (2018). Analysis of antioxidant activities and phenolic contents in fruits of Mao (Antidesma sp.). KHON KAEN AGR. J., 46 SUPPL.1

Ibrahem, M.D.; Fathib, M.; Mesalhyd, S. and El-Atyc, A.M.A. (2010). Effect of dietary supplementation of inulin and vitamin $\mathrm{C}$ on the growth, hematology, innate immunity, and resistance of Nile tilapia (Oreochromis niloticus). Fish and Shellfish Immunology, 29: 241-246. https://doi.org/10.1016/j.fsi.2010.03.004 
Judprasong, k.; Charoenkiatkul, S.; Thiyajai, P. and Sukprasansap, M. (2013). Nutrients and bioactive compounds of Thai indigenous fruits. Food Chemistry, 140(3): 507-512. https://doi.org/10.1016/j.foodchem.2013.01.057

Kamolrat, N. and Chopjit, P. (2018). Effect of Mao juice (Antidesma sp.) to Preventing Streptococcus spp. in Nile tilapia (Oreochromis niloticus). Agricultural Sci. J., 49: (3) (Suppl.): 182-186

Omnes, M.H.; Goasduff, J.L.; Delliou, H.L. et al. (2017). Effects of dietary tannin on growth, feed utilization and digestibility, and carcass composition in juvenile European seabass (Dicentrarchus labrax L.). Aquaculture Reports, 6: 21-27. https://doi.org/10.1016/j.aqrep.2017.01.004

Peng, C.; Lin, Z.; Lin, G. and Chen, S. (2006). The anti-photooxidation of anthocyanins-rich leaves of a purple rice cultivar. Sci China C Life Sci., 49(6): 54351. doi: 10.1007/s11427-006-2022-1.

Perera, R.P.; Johnson, S.K.; Collins, M.D. and Lewis, D.H. (1994). Streptococcus iniae associated with mortality of Tilapia nilotica x T. aurea Hybrids. J. Aquat. Anim. Health., 6: 335-340.

Puangpronpitag, D.; Areejitranusorn, P.; Boonsiri, P.; Suttajit, M. and Yongvanit, P. (2008). Antioxidant activities of polyphenolic compounds isolated from Antidesma thwaitesianum Mull. Arg. seeds and marces. J. Food Sci., 73: 648-53. DOI: 10.1111/j.1750-3841.2008.00951.x

Pungpang, S.; Boonprab, K.; Tunkijjanukij, S. et al. (2007). Effect of bacteria isolated from fish culture ponds on inhibition of Streptococcus agalactiae, the pathogenic bacteria in Nile tilapia (Oreochromis niloticus). Agriculture Sci. J., 38(6): 571-580

Sakhunkhu, S. and Sudham, N. (2014) . Study on mao luang (Antidesma sp.) genetically diversity using AFLP technique and comparison of type and quantities of antioxidants substance in mao luang leaves. KHON KAEN AGR. J., 42 SUPPL. 1

Shoemaker, C.A.; Evans, J.J. and Klesius, P.H. (2000). Density and dose: factors affecting mortality of Streptococcus iniae infected tilapia (Oreochromis niloticus). Aquacult., 188: 229-235. https://doi.org/10.1016/S0044-8486(00)00346-X

Sirimanaponga, W.; Kim, D.; Thompsonb, A. P. et al. (2018). Streptococcus agalactiae infection kills red tilapia with chronic Francisella noatunensis infection more rapidly than the fish without the infection. Fish \& Shellfish Immunology, 81: 221-232. https://doi.org/10.1016/j.fsi.2018.07.022

Suanyuk, N.; Kong, F.; Ko, D.; Gilbert, G.L. and Supamattaya, K. (2008). Occurrence of rare genotypes of Streptococcus agalactiae in cultured red tilapia Oreochromis sp. and Nile tilapia $O$. niloticus in Thailand-Relationship to human isolates. Aquaculture., 284(1-4): 35-40. https://doi.org/10.1016/j.aquaculture. 2008. 07.034 